\title{
Current practices of diagnostic techniques requir- ing the use of ophthalmic drugs among KwaZulu- Natal optometrists*
}

\author{
KP Mashige ${ }^{\dagger}$ and KS Naidoo
}

\author{
$\dagger, \star$ Discipline of Optometry, School of Physiotherapy, Sport Science and Optometry, University of \\ KwaZulu-Natal, Private Bag X 54001, Durban, 4000 South Africa \\ †>mashigek@ukzn.ac.za>
}

Received 6 April 2009; revised version accepted 27 October 2009

\begin{abstract}
In an endeavour to improve the quality of optometric eye care services in South Africa, the scope of practice was expanded to include the use of ocular diagnostic procedures such as gonioscopy that require the use of ophthalmic drugs. The purpose of this study was to assess the practices of specific diagnostic techniques (contact tonometry, $78 \mathrm{D} / 90 \mathrm{D}$ lens fundus examination, binocular indirect ophthalmoscopy and gonioscopy) requiring the use of ophthalmic drugs among optometrists in KwaZulu-Natal (KZN) province. These specific techniques are referred to as diagnostic procedures in this article. A questionnaire containing information on demography and practice of these specific techniques was sent to all $213 \mathrm{KwaZulu-Natal} \mathrm{reg-}$ istered optometrists who owned private practices. One hundred and thirty two completed questionnaires were received, a response rate of $62 \%$. One hundred and seventeen $(55 \%)$ of the questionnaires were included in the analysis of which $55 \%$ of the respondents were females and $45 \%$ were males. Sixty two optometrists $(53 \%)$ were certified in diagnostic procedures but many procedures were not being practiced. These procedures and the percentage respondents were: Contact tonometry $(60 \%)$, $78 \mathrm{D} / 90 \mathrm{D}$ lens fundus examination $(60 \%)$, binocular indirect ophthalmoscopy (84\%) and gonioscopy $(78 \%)$. Also, among these certified respondents (62

optometrists), a significant proportion (60\%) disagreed when asked if they were confident and proficient in performing the relevant diagnostic procedures. Many, (61\%) agreed that lack of incentives discouraged them from routinely performing the procedures. More than half (58\%), agreed that chair time was an important factor in deciding whether or not to perform these diagnostic procedures. Of the total respondents (117), 86\% agreed that they were confident about the accuracy of their referrals and less than half (45\%) disagreed that diagnostic procedures should be the sole responsibility of ophthalmologists. Less than half (48\%) agreed that diagnostic procedures should be incorporated into routine eye examinations. This study indicates that the performance of these diagnostic procedures was limited despite many optometrists having the necessary educational certification. It is recommended that initiatives that can be translated into practical action such as CPD workshops should pay greater attention to the improvement of diagnostic skills and practice. In addition, further education or opportunities emphasizing the importance of performing these diagnostic procedures over financial gains and time constraints are warranted.

Keywords: Scope of practice of optometry, specific diagnostic procedures, ophthalmic diagnostic drugs and optometry
\end{abstract}

${ }^{\dagger}$ BSc (Wits), BOptom (UDW), CAS (NewEnCo), MOptom (UKZN)

\$BSc, BOptom (UDW), MPH (Temple), OD (PCO)

*This paper forms part of research for the degree Master in Optometry (MOptom) at the University of KwaZulu-Natal undertaken by KP Mashige with the supervision of Professor KS Naidoo 


\section{Introduction}

Although optometrists have increasingly become an accepted part of a truly comprehensive health care team, their scope of practice differs worldwide ${ }^{1}$. Several studies ${ }^{2-6}$ have reported the key role that optometrists performed in the detection and management of ocular diseases including the use of ocular diagnostic drugs and procedures. Comparative studies ${ }^{7-8}$ conducted in the United Kingdom to assess aspects of clinical examination procedures have shown good agreements between optometrists and ophthalmologists. Diagnostic procedures that require drugs such as topical anesthetics, mydriatic and cycloplegic agents include intraocular pressure (IOP) measurement with contact tonometry, $78 \mathrm{D} / 90 \mathrm{D}$ lens and binocular indirect ophthalmoscopy (BIO) for fundus examination and gonioscopy. The use of these procedures in the diagnosis of eye diseases has become an integral part of optometric eye care services in South Africa ${ }^{9}$. This was considered a necessary step in order to combat the problem of the low level of eye care delivery in underserved communities, particularly the rural areas ${ }^{9}$.

In response to the new practice laws allowing South African optometrists to use procedures involved in the use of ophthalmic diagnostic drugs, tertiary institutions offering optometry have modified their curricula to incorporate diagnostic procedures within their four year programmes ${ }^{9}$. Therefore graduating students who had the advantage of using diagnostic procedures in their curricula are expected to incorporate the full range of these procedures in their practice. Also, optometrists who qualified before diagnostic components were incorporated into the curricula were afforded additional training through the Certificate of Advanced Studies in Ocular Disease and Pharmaceutical Application course (CAS), offered by New England College of Optometry and the Graduate Institute of Optometry (GIO). Studies ${ }^{10,11}$ in other countries such as the UK and the USA have reported that the implementation of these diagnostic procedures in optometry has resulted in a more costeffective and efficient eye care service.

Tonometry can be achieved by non-contact or contact methods of examination, with the contact methods usually providing more accurate and reliable results $^{12}$. The accurate assessment of IOP is regarded as one of the crucial diagnostic and management criteria for diseases such as glaucoma. The current gold standard of performing tonometry is the Goldmann applanation method ${ }^{13}$. With the high prevalence of glaucoma worldwide ${ }^{14}$, optometrists can play an important role in the early detection and referral of the condition for further management through properly conducting tonometry.

The $78 \mathrm{D} / 90 \mathrm{D}$ is a double aspheric lens that allows for a stereoscopic examination of the retina, particularly the estimation of the cup to disc ratio and its depth through a dilated pupil, using a slit lamp biomicroscope ${ }^{15}$. A study by Zheng and $\mathrm{He}^{16}$ found that the $78 \mathrm{D}$ lens examination showed smaller inter-observer variability compared with direct ophthalmoscopy in assessing the vertical cup to disc ratio in 475 eyes of 257 randomly selected subjects. The study concluded that the $78 \mathrm{D}$ lens was a more cost-effective and repeatable method of optic disc estimation in clinical and screening assessment ${ }^{16}$. This is useful for the differentiation between glaucomatous and normal optic nerve discs.

BIO permits a view of the fundus as far peripherally as the ora serrata ${ }^{17}$. Also, the technique can only be performed if the pupil of a patient has been dilated. Dhaliwal et $a l^{18}$ concluded in their study at the Edinburgh Royal Infirmary that BIO showed better sensitivity than wide-field digital retinal imaging in detecting mild forms of retinopathy of prematurity (ROP) in 81 infants. The authors therefore, concluded that BIO is important for a comprehensive retinal examination of the peripheral fundus to detect retinal breaks and other signs of ocular and systemic diseases ${ }^{17,} 18$.

Gonioscopy is a technique used to visualize the anterior chamber angle using a gonio-lens ${ }^{19}$ for the assessment, classification and management of potentially blinding angle closure glaucoma, a leading cause of irreversible blindness ${ }^{19}$. Angle closure glaucoma could result from ocular trauma, iris hypoplasia and anterior synechiae et cetera, leading to potential visual loss from glaucoma ${ }^{20}$. A study by Chakravarti and Spaeth ${ }^{21}$ involving a retrospective chart review of 322 eyes showed that gonioscopy was one of the useful techniques used in detecting primary angle closure glaucoma. Despite recent advances in anterior segment imaging, gonioscopy still remains one of the reliable and widely used angle and anterior segment examination techniques ${ }^{22}$. Gonioscopy is also impor- 
tant in diagnosing pigmentary glaucomas and other problems such as iris tumours ${ }^{22}$.

A thorough review of the literature did not reveal any previous studies relevant to our topic. To the best of our knowledge, this is the first study in South Africa (albeit from the province of KwaZulu-Natal only) to assess the practices of specific diagnostic techniques that require the use of ophthalmic drugs. The specific techniques investigated are contact tonometry, 78 D/90 D lens fundus examination, binocular indirect ophthalmoscopy (BIO) and gonioscopy and are referred to as diagnostic procedures in this study.

\section{Methodology}

This was a descriptive cross-sectional survey which targeted all the optometrists in KwaZulu-Natal owning their own private practices in 2007. A selfadministered questionnaire (Appendix 1) comprising questions on demography and practice of specific diagnostic procedures was used for data collection. Most of the questions were formulated following a thorough review of existing literature on the subject. The questionnaire included statements on several aspects of some diagnostic procedures such as the nature and frequency of performing the tests. Other options were included after the pilot study had identified factors that had not been listed. Practitioner details were extracted from a data base of optometrists maintained by the Health Professions Council of South Af- rica (HPCSA) and the Board of Healthcare Funders (BHF). Ethical approval for undertaking this study was obtained from the Research and Ethics Committee, Faculty of Health Sciences, University of KwaZulu-Natal. Written informed consent to participate in the study was obtained from all participants. For confidentiality, participants were asked not to write their names anywhere on the questionnaire. The data was captured and analyzed using the Microsoft Excel and Statistical Package for Social Sciences (SPSS 15.0). Analysis done included descriptive statistics such as frequencies and percentages and results are presented in tabular format.

\section{Results}

\section{Demographic details}

The study sample was one hundred and seventeen subjects $(N=117)$, and included $45 \%$ males and $55 \%$ females. There were 55\% Indians, 27\% Whites, $17 \%$ Blacks, and 1\% Coloured.

\section{Diagnostics Skills}

Fifty three percent of the total respondents had certification in diagnostic procedures. Of these, $60 \%$ reported not performing contact tonometry and 78 D/90 D lens fundus examination while $84 \%$ and $78 \%$ reported not performing BIO and gonioscopy respectively. The responses to the performance and frequency of diagnostic procedures are reported in Table 1.

Table 1: The percentages of the optometrists using specific diagnostic procedures are provided here. Also, the frequencies of use of each procedure are shown. The most commonly practiced procedures were contact tonometry (40\%) and $78 \mathrm{D} / 90 \mathrm{D}$ lens fundus examination $(40 \%)$ and the least was BIO $(16 \%)$.

\begin{tabular}{|c|c|c|c|c|c|}
\hline \multirow[t]{3}{*}{ Diagnostic procedure } & \multirow[t]{2}{*}{ No } & \multirow[t]{2}{*}{ Yes } & \multicolumn{3}{|c|}{$\begin{array}{l}\text { Frequency of performing the } \\
\text { technique among those who } \\
\text { reported "Yes" }\end{array}$} \\
\hline & & & $\begin{array}{l}\text { First } \\
\text { visit }\end{array}$ & $\begin{array}{l}\text { Every } \\
\text { visit }\end{array}$ & $\begin{array}{l}\text { Only if } \\
\text { indicated }\end{array}$ \\
\hline & $\begin{array}{l}\text { Number } \\
(\%)\end{array}$ & $\begin{array}{l}\text { Number } \\
\text { (\%) }\end{array}$ & $\begin{array}{l}\text { Number } \\
(\%)\end{array}$ & $\begin{array}{l}\text { Number } \\
(\%)\end{array}$ & $\begin{array}{l}\text { Number } \\
(\%)\end{array}$ \\
\hline Contact tonometry & $\begin{array}{l}37 \\
(60)\end{array}$ & $\begin{array}{l}25 \\
(40)\end{array}$ & $\begin{array}{l}7 \\
(28)\end{array}$ & $\begin{array}{l}6 \\
(24)\end{array}$ & $\begin{array}{l}13 \\
(52)\end{array}$ \\
\hline $\begin{array}{l}78 \mathrm{D} / 90 \mathrm{D} \text { lens fundus } \\
\text { examination }\end{array}$ & $\begin{array}{l}37 \\
(60)\end{array}$ & $\begin{array}{l}25 \\
(40)\end{array}$ & $\begin{array}{l}44 \\
(16)\end{array}$ & $\begin{array}{l}0 \\
(0)\end{array}$ & $\begin{array}{l}21 \\
(84)\end{array}$ \\
\hline $\mathrm{BIO}$ & $\begin{array}{l}52 \\
(84)\end{array}$ & $\begin{array}{l}10 \\
(16)\end{array}$ & $\begin{array}{l}2 \\
(20)\end{array}$ & $\begin{array}{l}0 \\
(0)\end{array}$ & $\begin{array}{l}8 \\
(80)\end{array}$ \\
\hline Gonioscopy & $\begin{array}{l}48 \\
(78)\end{array}$ & $\begin{array}{l}14 \\
(23)\end{array}$ & $\begin{array}{l}2 \\
(14)\end{array}$ & $\begin{array}{l}0 \\
(0)\end{array}$ & $\begin{array}{l}12 \\
(86)\end{array}$ \\
\hline
\end{tabular}


Sixty percent of optometrists, who were certified in diagnostic procedures, reported that they were not confident and proficient in performing the techniques while $61 \%$ reported that lack of incentives discouraged them from performing these diagnostic procedures. When asked if chair time was an important factor in performing the techniques, $60 \%$ agreed while $77 \%$ reported that they felt that patient satisfaction was enhanced by performing diagnostic techniques. The responses to the other questions on diagnostic procedures are illustrated in Table 2.

Of the total respondents included in the analysis $(N=117), 86 \%$ agreed that they were confident about the accuracy of their referrals. Forty five percent disagreed when asked if diagnostic procedures should be the sole responsibility of ophthalmologists while $48 \%$ reported that the procedures should be incorporated into a routine eye examination. Other responses are illustrated in Table 3.

Table 2: The percentage responses of optometrists who were certified in diagnostic procedures to various statements on the procedures are shown.

\begin{tabular}{|l|l|l|l|l|l|}
\hline Statement & $\begin{array}{l}\text { Strongly } \\
\text { agree }\end{array}$ & Agree & Neutral & Disagree & $\begin{array}{l}\text { Strongly } \\
\text { disagree }\end{array}$ \\
\cline { 2 - 6 } & $\begin{array}{l}\text { Number } \\
(\%)\end{array}$ & $\begin{array}{l}\text { Number } \\
(\%)\end{array}$ & $\begin{array}{l}\text { Number } \\
(\%)\end{array}$ & $\begin{array}{l}\text { Number } \\
(\%)\end{array}$ & $\begin{array}{l}\text { Number } \\
(\%)\end{array}$ \\
\hline $\begin{array}{l}\text { I am confident and proficient } \\
\text { in performing diagnostic } \\
\text { procedures }\end{array}$ & $\begin{array}{l}13 \\
(21)\end{array}$ & $\begin{array}{l}9 \\
(15)\end{array}$ & $\begin{array}{l}3 \\
(5)\end{array}$ & $\begin{array}{l}21 \\
(34)\end{array}$ & $\begin{array}{l}16 \\
(26)\end{array}$ \\
\hline $\begin{array}{l}\text { Lack of monetary incentives } \\
\text { discourages me from } \\
\text { performing diagnostic } \\
\text { procedures }\end{array}$ & 16 & $\begin{array}{l}22 \\
(36)\end{array}$ & $\begin{array}{l}5 \\
(8)\end{array}$ & $\begin{array}{l}12 \\
(19)\end{array}$ & $\begin{array}{l}7 \\
(11)\end{array}$ \\
\hline $\begin{array}{l}\text { Chair time is an important } \\
\text { factor in my decision to } \\
\text { perform diagnostic } \\
\text { procedures }\end{array}$ & $\begin{array}{l}22 \\
(36)\end{array}$ & $\begin{array}{l}15 \\
(24)\end{array}$ & $\begin{array}{l}7 \\
(11)\end{array}$ & $\begin{array}{l}9 \\
(15)\end{array}$ & $\begin{array}{l}9 \\
(15)\end{array}$ \\
\hline $\begin{array}{l}\text { I feel that patient satisfaction } \\
\text { is enhanced by performing } \\
\text { diagnostic procedures }\end{array}$ & $\begin{array}{l}25 \\
(40)\end{array}$ & $\begin{array}{l}23 \\
(37)\end{array}$ & $\begin{array}{l}12 \\
(19)\end{array}$ & $\begin{array}{l}2 \\
(3)\end{array}$ & $\begin{array}{l}0 \\
(0)\end{array}$ \\
\hline
\end{tabular}

Table 3: The percentage of responses to various statements on referral and management practices are shown.

\begin{tabular}{|c|c|c|c|c|c|}
\hline \multirow[t]{2}{*}{ Statement } & $\begin{array}{l}\text { Strongly } \\
\text { agree }\end{array}$ & Agree & Neutral & Disagree & $\begin{array}{l}\text { Strongly } \\
\text { disagree }\end{array}$ \\
\hline & $\begin{array}{l}\text { Number } \\
(\%)\end{array}$ & $\begin{array}{l}\text { Number } \\
(\%)\end{array}$ & $\begin{array}{l}\text { Number } \\
(\%)\end{array}$ & $\begin{array}{l}\text { Number } \\
(\%)\end{array}$ & $\begin{array}{l}\text { Number } \\
(\%)\end{array}$ \\
\hline $\begin{array}{l}\text { I am confident about the } \\
\text { accuracy of my referrals to } \\
\text { ophthalmologists }\end{array}$ & $\begin{array}{c}54 \\
(46)\end{array}$ & $\begin{array}{l}47 \\
(40)\end{array}$ & $\begin{array}{l}14 \\
(12)\end{array}$ & $\begin{array}{l}1 \\
(1)\end{array}$ & $\begin{array}{l}1 \\
(1)\end{array}$ \\
\hline $\begin{array}{l}\text { Diagnostic procedures should } \\
\text { be the sole responsibility of } \\
\text { ophthalmologists }\end{array}$ & $\begin{array}{l}5 \\
(4)\end{array}$ & $\begin{array}{l}14 \\
(12)\end{array}$ & $\begin{array}{l}46 \\
(39)\end{array}$ & $\begin{array}{l}25 \\
(21)\end{array}$ & $\begin{array}{l}27 \\
(23)\end{array}$ \\
\hline $\begin{array}{l}\text { Diagnostic procedures should } \\
\text { be incorporated into a routine } \\
\text { eye examination }\end{array}$ & $\begin{array}{l}19 \\
(16)\end{array}$ & $\begin{array}{l}37 \\
(32)\end{array}$ & $\begin{array}{l}42 \\
(36)\end{array}$ & $\begin{array}{l}12 \\
(10)\end{array}$ & $\begin{array}{l}7 \\
(6)\end{array}$ \\
\hline
\end{tabular}




\section{Discussion}

There has been great interest in the role that optometrists can play in the diagnosis and management of ocular diseases and as primary health care professionals. Various publications ${ }^{23-25}$ support the potential contribution from optometrists in this regard. The purpose of including diagnostic procedures such as applanation tonometry into the optometry curriculum was to ensure a comprehensive assessment of visual and ocular health status in patients ${ }^{9}$. While students take many courses in training, on graduation relatively few of these are applied in practice ${ }^{26}$. Within these courses students are taught many methods of diagnosis and management, but after graduation, it seems too many use only a few of these methods in practice ${ }^{27}$. There are many reasons for the above, which may include time, finances, lack of confidence or inexperience, et cetera ${ }^{27}$.

The respondents in this sample showed a fairly equitable gender distribution (55\% females and $45 \%$ males). However, the racial distribution did not reflect the distribution of the provincial population. This largely reflects historical legislation and imbalances. More than half $(53 \%)$ of the respondents were certified in diagnostic procedures; a positive trend at this early stage of legislation allowing optometrists the use of these procedures.

The majority $(60 \%)$ of the respondents who were certified in diagnostic procedures reported not performing contact tonometry. This could be due to the fact that many used other methods of IOP assessment such as non-contact tonometry which were probably considered to be simpler, requiring no use of local anesthetic $^{12,13}$. Also, many, (60\% and $\left.84 \%\right)$ did not routinely perform $78 \mathrm{D} / 90 \mathrm{D}$ and $\mathrm{BIO}$ fundus examination respectively (Table 1). This could be indicative that most optometrists preferred performing non-mydriatic direct ophthalmoscopy as a method of fundus examination and evaluation. The finding that $78 \%$ of respondents certified in diagnostic procedures did not perform gonioscopy could indicate that many used other non-invasive angle assessment approaches such as limbal anterior chamber depth measurement with the Van Herrick technique ${ }^{22}$.

Many respondents $(60 \%)$ who were certified in diagnostic procedures disagreed when asked if they were confident in performing diagnostics (Table 2).
Infrequent use of a procedure can lead to loss of skill which can lead to loss of confidence. The majority of respondents $(61 \%)$ agreed that lack of incentives discouraged them from performing diagnostics, suggesting that lack of remuneration may be a barrier to performing the techniques. Unfortunately, pricing structures are not set and medical schemes do not compensate optometrists separately for practicing these diagnostic procedures as it is seen as part of a comprehensive examination. This is consistent with the report that chair time was an important consideration when deciding whether or not to perform the procedures indicating this could be another factor preventing the performance of diagnostic techniques. Despite the above responses, many respondents $(77 \%)$ felt that patient satisfaction is enhanced by performing diagnostic procedures highlighting the fact that optometrists are aware of the importance of the relevant diagnostic procedures.

Of the total responses $(N=117)$ included in the analysis, $86 \%$ agreed that they were confident about the accuracy of their referrals (Table 3 ). These results are good, as comprehensive care of patients require accurate referrals between optometrists and ophthalmologists. Significantly, $45 \%$ of the respondents disagreed that diagnostic procedures should be the sole responsibility of ophthalmologists, while 39\% were neutral. This is what it should be as the provision of sufficient eye care requires both professionals. When asked whether these diagnostic procedures should be incorporated into a routine examination, a significant proportion $(48 \%)$ of the respondents answered in the affirmative and $36 \%$ were neutral.

The results of this survey indicate that too few practitioners engaged in techniques that constitute the eye disease diagnostic examination, despite being certified in those procedures. The diagnostic course in optometry departments should be treated as a teaching clinic associated with didactic courses similar to the relationships between courses and clinics in contact lenses, binocular vision, et cetera. However, it is seldom viewed as such. Instead, it is often viewed as an auxiliary training. Also, the proportion of clinical time allocated to the diagnostic course may be insufficient. It is suggested that this course must be allocated sufficient time and have the same status as contact lenses, binocular vision et cetera. Another approach would be to increase the emphasis and use of these 
procedures during all clinical activities in undergraduate education. This way students would emerge from their courses and would properly understand when and how to use these procedures and would probably use them more frequently despite the other issues such as chair time, et cetera. Further, those optometrists who have educational certification such as the CAS should engage in clinical rotations in hospitals and other clinical settings, as is done in the USA to gain the necessary skills and competencies in diagnostic procedures.

Current legislation allows optometrists to carry a bigger responsibility for different types of ocular conditions encountered in the clinical setting including the use of diagnostic procedures ${ }^{9}$. This is now a national expectation and standard. This also implies that optometrists will be held fully liable and responsible for diagnosing various conditions through the use of diagnostic procedures. Creative ways should be explored of developing the extent of the diagnostic course and practice ensuring that all coursework norms and clinical requirements are fully expressed and met. Also, a certain number of CPD credit points per year specifically in diagnostic procedures may be offered via hands-on workshops for optometrists. Perhaps the HPCSA and training institutions should assist on what should constitute acceptable minimum diagnostic procedures for eye care practice and how this may be achieved.

In order for optometrists to play a vital role in comprehensive eye care, a consistent and effective use of all the relevant diagnostic procedures should be encouraged, particularly given the limited success in recasting the image of the profession in a less subservient manner. Although the findings of this study cannot be generalized to optometrists nationwide, it does provide valuable information and suggests that more work is needed to ensure the introduction of these diagnostic procedures fully enhances the quality of patient care via South African optometrists.

\section{Acknowledgements}

The authors express appreciation to all the optometrists who participated in this study, as well as gratefully acknowledge the assistance of the African Vision Research Institute (AVRI) for collaborating in the development of the relevant questionnaire (see Appendix 1).

\section{References}

1. Di Stefano A. World optometry: the challenges of leadership for the new millennium. Optometry 200273 339-350.

2. Sundling V, Gulbrandsen P, Bragadottir R, Bakketeig LS, Jervell J, Straand J. Suspected retinopathies in Norwegian optometric practice with emphasis on patients with diabetes: a cross-sectional study. BMC Health Services Research 2008838.

3. Needle JJ, Petchey R, Lawrenson JG. A survey of the scope of therapeutic practice by UK optometrists and their attitude to an extended prescribing role. Ophthal Physiol Opt 200828 193-203.

4. Hulme SA, Tin UA, Hardy KJ, Joyce PW. Evaluation of a district-wide screening programme for retinopathy utilizing trained optometrists using slit-lamp and Volk lenses. Diabet Med $200219741-745$.

5. Prasad S, Kamath GG, Jones K, Clearkin LG, Phillips RP. Effectiveness of optometrist screening retinopathy using slit-lamp biomicroscopy. Eye 200115 595-601.

6. Grosvenor T. The role and scope of the primary care optometrist. In: Primary care optometry, 4th ed. Boston: Butterworth-Heineman, 2002 pp 43-49.

7. Hau S, Ehrlich D, Binstead K, Verma S. An evaluation of optometrists' ability to correctly identify and manage patients in an accident and emergency department of an eye hospital. Br J Ophthalmol 200791 437-440.

8. Banes MJ, Cullam LE, Bunce C, Xing W, Viswanathan A, Garway-Heath D. Agreement between optometrists and ophthalmologists on clinical management decisions for patients with glaucoma. Br J Ophthalmol 200690 579-585.

9. Health Professions Council of South Africa Act No.56 of 1974. Gov. Gazette. http://www.hpcsa.co.za/hpcsa/default. aspx?id=81. (Date accessed: 01.07.2006).

10. Harper R, Radi N, Reeves BC. Agreement between ophthalmologists and optometrists in optic disc assessment: training implications for glaucoma co-management. Graefes Arch Clin Exp Ophthalmol 2001239 342-350.

11. Beebe K. Optometric hospital practice. Optometry $2007 \mathbf{7 8}$ 194-196.

12. Abraham LM, Epasinghe NCR, Selva D, Casson R. Comparison of the Icare rebound tonometer with the Goldmann applanation tonometer by experienced and inexperienced tonometrists. Eye 200822 503-506.

13. Chihara E. Assessment of true intraocular pressure: the gap between theory and practical data. Surv Ophthalmol 2008 53 203-218.

14. Oduntan AO. Prevalence and causes of low vision and blindness worldwide. S Afr Optom 200564 44-54.

15. Kurtz D. Ocular health assessment. In: Carlson NB, Kurtz $\mathrm{D}$, eds. Clinical procedures for ocular examination, $3 \mathrm{rd}$ ed. New York: McGraw-Hill; 2004 pp 219-320.

16. Zheng Y, He M. New agreement in assessing vertical cup: disc ratio using a 78D lens with a slit-lamp eyepiece measuring graticule. Yan Ke Xue Bao 200732 53-57.

17. Alimanovic-Halilovic E. Correlation between refraction level and retinal breaks in myopic eye. Bosn J Basic Med Sci 20088 346-349. 
18. Dhaliwal C, Wright E, Graham C, McIntosh N, Fleck BW. Wide-field digital retinal imaging versus binocular indirect ophthalmoscopy for retinopathy of prematurity screening: a two-observer prospective, randomised comparison. $\mathrm{Br} J$ Ophthalmol 200993 355-359.

19. Friedman DS, He M. Anterior chamber angle assessment. Surv Ophthalmol 200853 250-273.

20. Sakata LM, Lavanya R, Friedman DS, Aung HS, Gao H, Kumar RS, Foster PJ, Aung T. Comparison of gonioscopy and anterior segment ocular coherence tomography in detecting angle closure in different quadrants of the anterior chamber angle. Ophthalmology 2008 115 769-774.

21. Chakravarti T, Spaeth GL. The prevalence of myopia in eyes with angle closure. J Glaucoma 200716 642-3.

22. Nolan W. Anterior segment imaging: ultrasound biomicroscopy and anterior segment optical coherence tomography. Curr Opin Ophthalmol 200819 115-121.
23. Hau S, Ehrlich D, Binstead K, Verma S. An evaluation of optometrists' ability to correctly identify and manage patients in an accident and emergency department of an eye hospital. Br J Ophthalmol 200791 437-440.

24. Banes MJ, Cullam LE, Bunce C, Xing W, Viswanathan A, Garway-Heath D. Agreement between optometrists and ophthalmologists on clinical management decisions for patients with glaucoma. Br J Ophthalmol 200690 579-585.

25. Soroka M, Krumholz D, Bennett A. The practice of optometry: National Board of Examiners in Optometry Survey of Optometric patients. Optom Vis Sci 200683 E625-E636.

26. Oduntan AO. Thirty years of optometric education at Turfloop (1975-2005): A historical and educational overview. $S$ Afr Optom 200665 34-40.

27. Oduntan AO, Louw A, Moodley VR, Richter M, Von Poser P. Perceptions, expectations, apprehensions and realities of graduating South African optometry students (PEAR study, 2006). S Afr Optom 200766 94-108.

\section{Appendix 1}

Dear Participant,

This survey is being conducted to establish the practices of specific diagnostic techniques requiring the use of ophthalmic drugs. The specific techniques being investigated are contact tonometry, 78 D/90 D, BIO and gonioscopy and are referred to as diagnostic procedures in this survey. Please write the corresponding number that best describes your response on the right side of the table.

\begin{tabular}{|l|l|}
\hline 1. Please indicate your gender: M [1] F [2] & \\
\hline 2. Please indicate your race group: Black [1] Indian [2] Coloured [3] White [4] & \\
\hline 3. Are you certified in diagnostic procedures? Yes [1] No [2] & \\
\hline For questions 4-7, please indicate which of the following diagnostic procedures are \\
performed in your practice? (Please use the following keys: Yes $=$ [1], No $=[2])$ & \\
\hline 4. Contact tonometry & \\
\hline 5. 78 D/90 D lens fundus examination & \\
\hline 6. Binocular indirect ophthalmoscopy (BIO) & \\
\hline 7. Gonioscopy \\
\hline For questions 8-11, please indicate how often the following diagnostic procedures are \\
performed. (Please use the following keys: First visit [1] Every visit [2] Only when \\
indicated [3])
\end{tabular}




\begin{tabular}{|l|l|}
\hline 8. Contact tonometry & \\
\hline 9. $78 \mathrm{D} / 90 \mathrm{D}$ lens fundus examination & \\
\hline 10. Binocular indirect ophthalmoscopy & \\
\hline 11. Gonioscopy & \\
\hline Strongly agree $=1$, Agree $=2$, Neutral $=3$, Disagree $=4$, Strongly disagree $=5$. & \\
\hline 12. I am confident and proficient in performing diagnostic procedures & \\
\hline 13. Lack of incentives discourages me from performing diagnostic procedures & \\
\hline 14. Chair time is an important factor in my decision to performing diagnostic \\
procedures
\end{tabular}

